\title{
The Balanced Scorecard, Alphabet of the Modern Management: From Concept to Implement
}

\author{
Akbar Javadian Kootanaee ${ }^{1, *}$, Hamidreza Javadian Kootanaee ${ }^{2}$, \\ Hosein Hoseinian ${ }^{3}$ and Hamid Foladi Talari ${ }^{4}$
}

\begin{abstract}
The balanced scorecard is one of the most successful, endurable management concepts in recent years. The balanced scorecard is a performance measurement tool developed in 1992 by Harvard Business School professor Robert S. Kaplan and management consultant David P. Norton. Kaplan and Norton's research led them to believe that traditional financial measures, such as return on investment, could not provide an accurate picture of a company's performance in the innovative business environment of the 1990s. The balanced scorecard provides a framework for managers to use in linking different types of measurements together. Kaplan and Norton recommend looking at the business from four perspectives: the customer's perspective; an internal business perspective; an innovation and learning perspective; and the financial (or shareholder's) perspective. Using the overall corporate strategy as a guide, managers derive three to five goals related to each perspective. Then they develop specific measures to support each goal.
\end{abstract}

${ }^{1}$ University of Mysore and Department of Accounting, Islamic Azad University, e-mail: Akbar.javadiankootanaee@yahoo.com

* Corresponding Author.

2 Faculty of Accounting, Islamic Azad University of Tehran Branch, e-mail: Hamidreza.Javadian@yahoo.com

3 E-mail: Hhossein2007@yahoo.com

${ }^{4}$ E-mail: Hamid_foladi@yahoo.com

Article Info: Received : September 3, 2012. Revised : September 29, 2012 Published online : January 20, 2013 
JEL classification numbers: L16, L90, M40, M11

Keywords: balanced scorecard, management accounting, financial measures, Implement of BSC, performance measures

\section{Introduction}

The balanced scorecard is a performance measurement tool developed in 1992 by Harvard Business School professor Robert S. Kaplan and management consultant David P. Norton. Kaplan and Norton's research led them to believe that traditional financial measures, such as return on investment, could not provide an accurate picture of a company's performance in the innovative business environment of the 1990s. But rather than forcing managers to choose between "hard" financial measures and "soft" operational measures-such as customer retention, product development cycle times, or employee satisfaction-they developed a method that would allow managers to consider both types of measures in a balanced way. "The balanced scorecard includes financial measures that tell the results of actions already taken," Kaplan and Norton explained in their 1992 Harvard Business Review article. "And it complements the financial measures with operational measures on customer satisfaction, internal processes, and the organization's innovation and improvement activities-operational measures that are the drivers of future financial performance.", [3].

The balanced scorecard provides a framework for managers to use in linking different types of measurements together. Kaplan and Norton recommend looking at the business from four perspectives: the customer's perspective; an internal business perspective; an innovation and learning perspective; and the financial (or shareholder's) perspective. Using the overall corporate strategy as a guide, managers derive three to five goals related to each perspective. Then they develop specific measures to support each goal. Ideally, the scorecard helps managers to clarify their vision for the organization and translate that vision into measurable actions that employees can understand. It also enables managers to balance the concerns of various stakeholders in order to improve the company's overall performance. "The balanced scorecard is a powerful concept based on a simple principle: managers need a balanced set of performance indicators to run an organization well," Paul McCunn wrote in Management Accounting. "The indicators should measure performance against the critical success factors of the business, and the 'balance' is the balancing tension between the traditional financial and non-financial operational, leading and lagging, and action-oriented and monitoring measures."

The balanced scorecard concept has enjoyed significant success since its introduction. Part of the balanced scorecard's popularity can be attributed to the fact that it is consistent with many common performance improvement initiatives undertaken by companies, such as continuous improvement, cross-functional teamwork, or customer-supplier partnering. It complements these initiatives by 
helping managers understand the complex interrelationships among different areas of the business. By linking the elements of a company's competitive strategy in one report, the balanced scorecard points out situations where improvement in one area comes at the expense of another. In this way, the scorecard helps managers make the decisions and tradeoffs necessary to succeed in today's fast-paced and competitive business environment, [10].

\section{History of the BSC}

In 1990 Robert S. Kaplan, a professor of accounting at the Harvard Business School, and David P. Norton, cofounder of a Massachusetts-based strategy consulting firm called Renaissance Worldwide, Inc., conducted a year-long research project involving 12 large companies. The original idea behind the study, as Anita van de Vliet explained in Management Today, was that" relying primarily on financial accounting measures was leading to short-term decision-making, over-investment in easily valued assets (through mergers and acquisitions) with readily measurable returns, and under-investment in intangible assets, such as product and process innovation, employee skills, or customer satisfaction, whose short-term returns are more difficult to measure.", [3].

Kaplan and Norton looked at the way these companies used performance measurements to control the behavior of managers and employees. They used their findings to devise a new performance measurement system that would provide businesses with a balanced view of financial and operational measures. Kaplan and Norton laid out their balanced scorecard approach to performance measurement in three Harvard Business Review articles beginning in 1992. Before long, the balanced scorecard had become one of the hottest topics at management conferences around the world. In fact, the Harvard Business Review called it one of the most important and influential management ideas of the past 75 years. In 1996 Kaplan and Norton expanded upon their original concept in a book, The Balanced Scorecard: Translating Strategy into Action.

In 1999 Kaplan and Norton introduced computer resources to provide information and support for organizations that adopt the balanced scorecard. For example, Norton's consulting firm, Renaissance Worldwide, Inc., and Gentia Software formed the Balanced Scorecard Technology Council. This virtual users group sponsors a web site that provides research, product information, and a forum for ideas. Kaplan and Norton also founded an organization called the Balanced Scorecard Collaborative "to facilitate worldwide awareness, use, enhancement, and integrity of the Balanced Scorecard as a value-added management process.", [10]. 


\section{The Four Perspectives of the Balanced Scorecard}

The balanced scorecard's first perspective is the financial aspect of business. It measures the effectiveness of actions taken in the implementation and execution of the strategy to the bottom line improvement. Many different measures are used to look mostly at profitability of the business, for example, return on capital employed or economic value added. Alternative simpler measures can sales growth or generation of cash flow. They are used to summarize the readily measurable economic consequences and to use them as one tools to assure the current financial needs and goals of the company. While the financial perspective is important is current status of the company the main flaw as individual information that it is based on the past and gives no information about current and future efforts to improve and reach objectives. It doesn't give any information about the actions taken to improve the company's results, whether the customer is happy about the service or product and if the internal process of the organization is effective. This is why you need the balance in the scorecard to have perspectives into more than one dimension not only in the organization, but also in time.

The internal processes measures focus on the internal process and especially the ones that will have the most impact on customer satisfaction and achievement of organizations financial objectives. The aim is to identify the critical internal processes in which the organization must excel. The processes enable organizations to:

- Deliver the value propositions that will attract and retain customers in targeted market segments, and

- Satisfy shareholders expectations of excellent financial returns.

As Kaplan and Norton say (1996) the internal-business-process perspective reveals two fundamental differences between traditional and the balanced scorecard approach to performance measurement. Traditional approaches attempt to monitor and improve existing business processes. This is where the evaluation processes to meet the needs of the financial and customer aspects can many times end with the creation of new business processes to assure meeting the real demands. The second is to incorporate an innovation process in the internal business process perspective to not only assure meeting short term goals, but also creating a process to assure focus in the long term goals through processes.

The learning and growth perspective identifies the infrastructure that the organization needs to create long-term growth and improvement. The customer and internal-business-process perspectives identify factors critical to achieve current and future success, but businesses are unlikely to be able to met long term targets for customer and internal-business-process with today's technology and capabilities. With global competition, the requirement of companies continues improvement to deliver value to the customer and shareholder is a reality. 
Figure 1: Four perspectives of balanced scorecard

Organizational learning comes from three sources: people, systems and organizational procedures. While identifying the other three perspectives, the gap between the existing capabilities of people, systems and procedures and what is needed for creating great results are revealed.

To close these gaps the learning and growth perspectives is to help these gaps to be filled to achieve future success via training, enhancing systems and aligning procedures and routines.

In the balanced scorecard's customer perspective the aim is to identify the customer and market segments in which in which business units will compete and the measure of the business unit's performance in these targeted segments. Usually the measures used are core and generic ones such as customer satisfaction, customer retention, new customer acquisition, customer profitability and market share in targeted segments. But the customer perspective should also include specific measures of the value proposition of the company's. These could for example for an online store delivery speed or reclamation process satisfaction to drive the company's own value propositions fulfillment. This can also be the future orientated measures, for example, introduction of new services to drive future success and anticipation of customer needs. The customer perspective enables business unit managers to articulate the customer and market-based strategy that will deliver superior future financial returns, [1].

\section{Balanced Scorecard Advantages}

The first advantage of using the balanced scorecard method is that by looking at four aspects of a company's performance, you really do get a balanced view of company performance. Unlike traditional methods of tracking the financial health of a business, the balanced scorecard gives you a full picture as to whether your company is meeting its objectives. While it may seem that a company is doing well financially, it may be that customer satisfaction is down, employee training is inadequate, or that the processes are outdated.

Second, by using a balanced scorecard approach, the immediate future isn't the only thing being evaluated. Often, when an accountant sees the financial bottom line (perhaps the company isn't doing well), suggestions are given that are immediate, but do not look at the long-term. Using balanced scorecards allows for stakeholders to determine the health of short, medium, and long term objectives at a glance.

Finally, by using a balanced scorecard, a company can be sure that any strategic action implemented matches the desired outcomes. Will raising the price of a product help the bottom line of the company in the long run? It might, if the 
customer is satisfied with that product, or if the processes involved with creating that product make the product of a higher quality, [9].

\section{Balanced Scorecard Disadvantages}

While there are many advantages to using balanced scorecards in your accounting toolbox, there are a few disadvantages to the method as well. First, the balanced scorecard takes forethought. It is not a tool you can just think up one night to solve a problem. Instead, it is recommended that you hold a meeting to plan out what goals you would like to see your company reach in each of the four above areas. Once you have clearly stated objectives, you can then begin to break down these objectives in what you will need, financially, to bring these objectives to fruition.

Second, while the balanced scorecard gives you an overall view of the four areas for concern in business growth and development, these four areas do not paint the whole picture. The financial information included on the scorecard is limited. Instead, to be successfully implemented, the balanced scorecard must be part of a bigger strategy for company growth that includes meticulous accounting methods.

Finally, many companies use metrics that are not applicable to their own situation. It is vitally important when using balanced scorecards to make the information being tracked applicable to your needs. Otherwise, the metrics will be meaningless, [9].

\section{Steps of Building and Implementing Balanced Scorecard}

\subsection{Part 1: Building a Balanced Scorecard System}

Phase One: Building The Scorecard, consists of six steps. Step One is an Assessment of the organization's foundations, its core beliefs, market opportunities, competition, financial position, short and long-term goals, and an understanding of what satisfies customers. Many organizations have completed this basic step, typically as a self-assessment at an off-site workshop for managers and executives. Usually, an organization's strengths, weaknesses, opportunities, and threats are developed, discussed, and documented. There is no need to repeat this "environmental scan" of an organization if the information is available and current, say within the past six months. It is important, however, to ensure that the assumptions that underlie the basis for the organization's existence and its business strategies are still valid and sound.

Step Two is the development of overall Business Strategy. In larger organizations, several overarching strategic themes are developed that contain specific business strategies. Examples of common strategic themes include: Build 
the Business, Improve Operational Efficiency, and Develop New Products. For public sector organizations, strategic themes might include: Build A Strong Community, Improve Education, Grow the Tax Base, and Meet Citizen Requirements. In addition to describing what the approach is, business strategy, by elimination, identifies what approaches have not been selected. Strategy is a hypothesis of what we think will work and be successful. The remaining steps in the scorecard-building phase provide the basis for testing whether our strategies are working, how efficiently they are being executed, and how effective they are in moving the organization forward toward its goals.

Step Three is a decomposition of business strategy into smaller components, called Objectives.

Objectives are the basic building blocks of strategy -- the components or activities that make up complete business strategies. Southwest Airlines developed a business strategy to compete successfully in the crowded commercial airline market. The business strategy of Southwest includes the following components: innovation and speed in the redefinition of a marketplace; short-haul, high frequency, point-to-point routing (a significant departure from traditional hub-and-spoke routing); a high proportion of leased aircraft; a very simple fare structure; and electronic ticketing.

In Step Four, a Strategic Map of the organization's overall business strategy is created. Using cause effect linkages (if-then logic connections), the components (objectives) of strategy are connected and placed in appropriate scorecard perspective categories. The relationship among strategy components is used to identify the key performance drivers of each strategy that, taken together, chart the path to successful end outcomes as seen through the eyes of customers and business owners. Figure 2, a strategic map for a transactions-based company, shows how an objective (effect) is dependent on another objective (cause), and how, taken together, they form a strategic thread from activities to desired end outcomes. A strategy map is an excellent way to describe the customer value chain.

\section{Private Sector Strategic Map}

Figure 2: Strategic Mapping

In Step Five, Performance Measures are developed to track both strategic and operational progress. To develop meaningful performance measures, one has to understand the desired outcomes and the processes that are used to produce outcomes. Desired outcomes are measured from the perspective of internal and external customers, and processes are measured from the perspective of the process owners and the activities needed to meet customer requirements. 
Relationships among the results we want to achieve and the processes needed to get the results must be fully understood before we can assign meaningful performance measures.

In Step Six, New Initiatives are identified that need to be funded and implemented to ensure that our strategies are successful. Initiatives developed at the end of the scorecard building process are more strategic than if they are developed in the abstract.

How long does it take to build a scorecard system? Depending on the size of the organization, two to four months is typical, six weeks is possible. The drivers of "shorter rather than longer" are: senior leadership support and continuous commitment, currency of existing assessment information, size of the organization, availability of scorecard team members, willingness to change and embrace new ideas, level of organization pain that is driving the score carding journey, and facilitation support. (At the risk of sounding self-serving, the journey goes faster and smoother when outside expert training and facilitation assistance are used.)

A Balanced Scorecard system provides a basis for executing good strategy well and managing change successfully. Building a Balanced Scorecard performance system using the framework described here will cause people to think differently (more strategic) about their organization and their work. For many, this is a refreshing change to "strategic planning as usual." But it will also bring change in the way things are done, as new policies and procedures are developed and implemented.

For some, these changes can be troubling. The realization is that the Balanced Scorecard journey involves changing hearts and minds at least as much as it involves measuring performance, [8].

\subsection{Part 2: Implementing a Scorecard Performance System}

In this section, we discuss the steps involved in implementing the Balanced Scorecard, and include recommendations for creating a management system and sustaining the system once it is built.

By "implementing" we mean turning the strategy and the scorecard into a true management system and deploying, managing, and sustaining the newly created system. We use three steps to implement the scorecard: Automation, Cascading, and Evaluation.

Following the completion of the building steps (Steps One through Six), the critical few performance measures have been developed.

Precious strategic critical thinking is lost if this path is pursued.

Once we have a good set of strategic performance measures, a Performance Measurement information system is needed to collect and report performance data and transform the data into performance information. The distinction between data and information is important, as raw performance data is of little use to most people. 
Step Seven involves automating the Balanced Scorecard system, and consists of analyzing software options and user requirements to make the most cost effective software choice for today and to meet enterprise performance information requirements in the future. Software options range from spreadsheets and databases, designed to meet very simple enterprise reporting requirements, to full data warehouses, designed to link disparate information (performance and other) together in an integrated management system.

Step Eight involves cascading the corporate scorecard throughout the organization to business and support units, and ultimately to teams and individuals. Cascading means translating the corporate scorecard into department and division scorecards that are aligned with corporate strategy. In other words, aligning and translating corporate strategy throughout the organization. In a typical organization, separate scorecards are developed for each major department and support office, and these scorecards are linked to the corporate scorecard through objectives. Since objectives are the building blocks of strategies, the alignment of objectives aligns strategy as well.

Figure 3: Balanced Scorecard Institute Nine Steps To Success ${ }^{\mathrm{TM}}$ Framework for Building and Implementing a Balanced Scorecard

Step Nine involves evaluating the success of chosen business strategies. The key question is: Were the expected results achieved and why? Remember that strategies developed in Step Two of our Nine Steps to Success ${ }^{\text {TM }}$ framework were hypotheses of how an organization believes it creates value for customers and stakeholders. Adjustments to strategy (and mission and vision, if necessary) are likely as performance information is analyzed and market competitive forces are considered. Creating an analysis feedback loop to test strategy assumptions is an important step and one that many organizations overlook in their strategic planning implementation. The evaluation step includes the following components: - Understanding why the results that were achieved were or were not achieved

- Ensuring that organizational learning and knowledge building are being incorporated into planning

- Making adjustments to existing strategies, services, and programs

- Replacing strategies with more cost-effective ones

- Eliminating programs and services that are not satisfying customer needs

- Linking planning to budgeting

The Nine Steps to Success framework is a disciplined way to develop the pieces needed to build a strategic management system. Now it is time to put the pieces 
together into a strategic management system and start using the system to produce the results, [8].

\subsection{Part 3: Building the Management System and Managing with the Balanced Scorecard}

Building and implementing a scorecard system is one thing; turning the scorecard into a used and useful management system is something else entirely. The key to transforming a scorecard into a management system is to start at the right level of granularity and "connect the dots" among the components of strategy (mission, vision, values, pains, enablers, strategic results and themes, and strategic objectives) and the components of operations (projects, processes, activities, and tasks), and the budget formulation and cost reporting processes.

The Balanced Scorecard gives us the ability to develop the aligned components of this strategic management system in an ordered, disciplined manner, [8].

\section{Implementation Pitfalls}

1. Confusion regarding primary performance drivers

Often, financial measures carry more weight within an organization than non-financials, but to drive through a holistic, long-term and sustainable strategic re-alignment, the needs of non-owner stakeholders (service users, service delivery partners, etc) should also be considered. This is particularly important where:

The business is adopting a value based management (VBM) approach;

Shareholder value maximization is the ultimate objective, and

The needs of non-financial stakeholders are material to the business.

These requirements should be analyzed explicitly and translated into scorecard measures.

2. Poorly defined metrics

Metrics can be classified as either Results Metrics or Process Metrics. Results Metrics are measures seen by the process customer. These are the most useful as a management tool, and are usually what appear on the scorecard. Process metrics are internal measures that cause the results metrics. Process metrics are most useful to improvement teams and focus attention on places where improvements will have the greatest impact.

Good metrics are:

-A reliable proxy for outcomes and stakeholder satisfaction;

-Weakness or deficit-oriented (have an ideal value of zero);

- Simple and easy to understand; 
-Well-documented, unambiguous, and consistent, with sound operational definitions;

- Timely and accessible to those who can best use them;

- Linked to an underlying data system that facilitates the identification of root causes of gaps in scorecard results, and

- Have a formal process for their continuous review and refinement.

3. Negotiated, rather than stakeholder focused performance targets

Although performance targets should be set according to current knowledge of the means used to achieve them, it is argued that such means are rarely known at the time of target setting - a 'chicken and egg' situation.

4. Lack of a delivery-level target deployment system

Financial systems are able to consolidate data generated at the transactional level and all financial measures can be communicated using a single metric. The same cannot be true of non-financial performance measures, which may be difficult to communicate in a consistent denomination.

5. No state-of-the-art improvement system is used

In theory, the strategic balanced scorecard has an built-in mechanism for verifying the validity of the causalities from which it has been deployed. However, in practice, organisations seldom have the time or resource to develop and follow through any required strategic realignment, particularly where considerable resources are already deployed. Computerised balanced scorecard systems may address this perceived shortcoming.

6. There is not, and cannot be a quantitative linkage between non-financial and expected financial results

It has been argued that efforts to undertake a meaningful quantitative analysis of both the impact of actions generating non-financial performance measures and the expected financial results, are not only difficult, but may be pointless. Diverting resources to develop alternative strategies or strategic objectives may be similarly misguided, for the same reasons, notably:

- The impact of apparently insignificant decisions

- The operation of the 'chaos' theory within businesses, and

- The potential existence of unknown and un-quantifiable time-lags between action and impacts, even where causality does exist.

7. Being inward looking and examining the impact of external discontinuities

One criticism leveled at the balanced scorecard is that the framework encourages an internal focus, although advocates argue that the scorecard manages external forces in two ways. First, these are considered when managers performing a SWOT (and/or similar approach) and competitor analysis to formulate strategy, and secondly many scorecard measures are, by their nature, calibrated against competitors.

Where there are significant changes in external conditions, management should assess how these have an impact on the scorecard and whether it needs to 
modify the objectives, measures and targets.

Despite its perceived limitations, it is unwise to write-off the value of the balanced scorecard approach. Experience has shown that, as organizations have bought into the scorecard theory, it has evolved from a simple performance measurement device, into a powerful framework which may be used:

- As a communication device

- As a driver and conduit for organizational culture change, and

- To implement, reinforce and continually refine an agreed strategic focus and business model throughout an organization.

At Shell, for example, the balanced scorecard approach has evolved into a robust framework that now forms the basis of employee appraisals, [7].

\section{Avoiding Potential Pitfalls}

Numerous organizations have implemented some version of the balanced scorecard since its introduction in 1992. But Professor Claude Lewy of the Free University of Amsterdam found that 70 percent of scorecard implementations failed. Many companies are attracted by the power and simplicity of the balanced scorecard concept, but then find implementation to be extremely time-consuming and expensive. Lewy admitted that the balanced scorecard can be an effective way of translating an overall strategy to the many parts of an organization. But he stressed that organizations must have a clear idea of what they want to accomplish, and be willing to commit the necessary resources, in order to implement the balanced scorecard successfully. Along with Lex du Mee of KPMG Management Consulting, Lewy conducted a study of seven European companies and came up with what he called the Ten Commandments of Balanced Scorecard Implementation.

In order to ensure an effective balanced scorecard implementation, Lewy and du Mee recommended that organizations obtain the commitment of a top-level sponsor as well as relevant line managers. The balanced scorecard initiative must be the top priority of the organization if implementation is to succeed. They also emphasized the importance of putting strategic goals in place before implementing the scorecard. Otherwise, the goals and measures included in the scorecard are likely to drive the wrong behavior. Lewy and du Mee also suggested that organizations try a pilot program before moving on to full-scale implementation. Testing the balanced scorecard in a few key business areas enables managers to make necessary changes and increase support for the initiative before involving the entire company. It is also important to provide information and training to employees prior to an organization-wide rollout.

Lewy and du Mee also warned managers against using the balanced scorecard as a way to achieve extra top-down control. Employees are unlikely to support the goals and measures if the scorecard is used as a "gotcha" by 
management. Another potential pitfall, according to the researchers, is trying to use a standardized scorecard. Instead, they stress that each organization must devote the time and resources to develop its own customized program. Lewy and du Mee found that balanced scorecard implementation was more likely to fail when companies underestimated the amount of training and communication required during the introductory phase, or the extra workload and costs involved with periodic reporting later on. Even though the balanced scorecard appears to be a simple idea, implementing it is likely to mean huge changes in an organization, [10].

\section{References}

[1] Front, Pekka, Work motivation through a balanced scorecard approach motivational leadership for the 21st century, (2010).

[2] R.S. Kaplan, Conceptual Foundations of the Balanced Scorecard, Harvard Business Review, (2010).

[3] R.S. Kaplan and D.P. Norton, The Balanced Scorecard- Measurement that Drive Performance, Harvard Business Review, (January- February, 1992).

[4] R.S. Kaplan and D.P. Norton, Putting the Balanced Scorecard to Work, Harvard Business Review, (January- February, 1993).

[5] R.S. Kaplan and D.P. Norton, Using Balanced Scorecard as A Strategic Management Systems, Harvard Business School Press, Boston, 1996a.

[6] R.S. Kaplan and D.P. Norton, Translating Strategy into action-the Balanced scorecard, Harvard Business School Press, Boston, 1996b.

[7] Liz Murby and Stathis Gould, Why Balanced Scorecards Sometimes Fail, CIMA Technical Report, (2005).

[8] Rohn and Halbach, Developing and Using Balanced Scorecard Performance Systems, Balanced Scorecards Institute, (2005).

[9] Ronda Roberts, Weighing the Pros and Cons of Balanced Scorecards, (2011).

[10] http://www.enotes.com/ 